\title{
Mediação de conflito escolar como ferramenta de prevenção ao bullying: ação em saúde pública
}

\author{
School conflict mediation as a tool to prevent bullying: public
} health action

\author{
Mediación de conflicto escolar como herramienta de \\ prevención al bullying: acción en salud pública
}

\author{
Michel Canuto de Sena ${ }^{1}$ \\ Fernando Moreira Freitas da Silva ${ }^{2}$ \\ Heitor Romero Marques ${ }^{3}$ \\ Paulo Roberto Haidamus de Oliveira Bastos ${ }^{4}$
}

${ }^{1}$ Doutorando e mestre em Saúde e Desenvolvimento da Região Centro-Oeste pela

Universidade Federal de Mato Grosso do Sul (UFMS). Especialista em Direito Civil e

Processo Civil pela Universidade Católica Dom Bosco (UCDB). Graduado em Direito pela Faculdade Mato Grosso do Sul (FACSUL). Professor de Bioética e Direito Civil. Bolsista Capes.

E-mail: canuto.fadir.ufms@gmail.com, Orcid: http://orcid.org/0000-0001-5317-2306.

${ }^{2}$ Doutorando em Direito do Estado pela Universidade de São Paulo (USP). Mestre em Direito Negocial pela Universidade Estadual de Londrina (UEL). Especialista em Direito

Empresarial pela Universidade Federal de Mato Grosso (UFMT). Especialista em Gestão

Pública pela Universidade de Cuiabá (UNIC). Especialista em Direitos Fundamentais e

Controle de Constitucionalidade pela Pontifícia Universidade Católica do Rio de Janeiro (PUC-Rio). Graduado em Direito pela UFMT. Juiz de Direito do Tribunal de Justiça do Estado de Mato Grosso do Sul e professor da Escola da Magistratura de Mato Grosso do Sul. E-mail:

fernandomoreira2103@gmail.com, Orcid: https://orcid.org/0000-0002-8503-5389.

${ }^{3}$ Doutorado em Desarrollo Local y Planteamiento Territorial pela Universidad Complutense de Madrid. Mestrado em Educação e Formação de Professores pela Universidade Católica

Dom Bosco (UCDB). Especialização em Filosofia e História da Educação pelas Faculdades Unidas Católicas de Mato Grosso (FUCMT). Graduação em Ciências e em Pedagogia pela

FUCMT. Graduação em Educação Moral e Cívica - Exame de Suficiência e graduação em Ciências de Primeiro Grau - Exame de Suficiência pela Universidade Federal de Goiás (UFG). Professor do Programa de Mestrado e Doutorado em Desenvolvimento Regional da UCDB. E-mail: heiroma@ucdb.br, Orcid: http://orcid.org/0000-0001-6487-7950.

${ }^{4}$ Doutor e mestre em Educação pela Pontifícia Universidade Católica de São Paulo (PUC-SP). Especialista em Farmácia, Área Hospitalar, pela Universidade Federal do Rio de Janeiro (UFRJ). Especialização em Metodologia pela Universidade Federal de Mato

Grosso do Sul (UFMS). Especialização em Curso de Aperfeiçoamento em Farmácia

Hospitalar (USP). Graduação em Farmácia Bioquímica pela UFMS. Professor titular

(Full Professor) da UFMS. Professor visitante (Visiting Researcher) do Programa de PósGraduação Stricto Sensu em Saúde e Desenvolvimento na Região Centro-Oeste da UFMS.

E-mail: phaidamus43@gmail.com, Orcid: http://orcid.org/0000-0002-8885-1461.

Multitemas, Campo Grande, MS, v. 25, n. 60, p. 45-69, maio/ago. 2020 
Resumo: A violência tem sido assunto de debate social e das agendas governamentais. Tais assuntos ficam mais sensíveis quando são tratados dentro das escolas ou até mesmo na casa das vítimas. Assim, o bullying, espécie de violência ainda não tipificada pelo Código Penal de 1940, passa a ser de grande valia nos discursos políticos, sociais e jurídicos. O objetivo da presente pesquisa é realizar reflexões sobre o bullying nas escolas, os reflexos na saúde pública e os desdobramentos com os familiares. A metodologia utilizada foi o estudo da arte, fazendo menção aos principais autores do ramo. Diante do exposto, verifica-se que o bullying está distante de ser assunto pacificado e que necessitam ser adotadas tanto lei quanto políticas públicas que o envolvam, pois ele traz gastos para os cofres públicos e desestabiliza as relações interpessoais.

Palavras-chave: mediação de conflitos; violência; bullying; responsabilidade civil.

\begin{abstract}
Violence has been a subject of social debate and of the government agendas. Such issues become more sensitive when treated within schools or even at the home of victims. Thus, bullying, a type of violence not yet typified by the Penal Code of 1940, becomes of great value in political, social and legal discourses. The purpose of the present research is to make reflections on bullying in schools, the reflexes in public health and the unfolding with the relatives. The methodology used was the study of art, making mention to the main authors of the branch. In light of the above, it is clear that bullying is far from being a pacified issue and both law and public policy involving it need to be adopted, as it brings expenditures to the public coffers and destabilizes interpersonal relationships.
\end{abstract}

Keywords: mediation of conflicts; violence; bullying; civil responsibility.

Resumen: La violencia ha sido tema de debate social y de las agendas gubernamentales. Tales asuntos se vuelven más sensibles cuando son tratados dentro de las escuelas o incluso en la casa de las víctimas. Así, el bullying, especie de violencia aún no tipificada por el Código Penal de 1940, pasa a ser de gran valor en los discursos políticos, sociales y jurídicos. El objetivo de la presente investigación es realizar reflexiones sobre el bullying en las escuelas, los reflejos en la salud pública y los desdoblamientos con los familiares. La metodología utilizada fue el estudio del arte, haciendo mención a los principales autores del ramo. Ante a lo expuesto, se verifica que el bullying está lejos de ser asunto pacificado y que se necesitan tanto ley como política pública que lo involucran, pues trae gastos a las arcas públicas y desestabiliza las relaciones interpersonales.

Palabras clave: mediación de conflictos; violencia; bullying; responsabilidad civil. 


\section{INTRODUÇÃO}

A vida em sociedade pode ser definida como uma percepção das relações interpessoais, decorrente do sentimento vivenciado pelos indivíduos, de acordo com suas normas e crenças. Desse modo, pode haver conflitos nas atividades corriqueiras de cada sujeito.

A escola tem se tornado palco de conflitos gerados por diferenças humanas e sociais. Nas escolas brasileiras, a violência envolvendo alunos e professores tem se tornado um problema de saúde pública, decorrente do comportamento violento, que, na maioria dos casos, está associado com o insucesso escolar, aumentando também as chances de comportamento agressivo e antissocial.

Diversos aspectos podem estar relacionados com a violência. A falta de políticas públicas adequadas, más influências, indisciplina no sistema de ensino e a ausência dos pais são alguns dos fatores que podem gerar reflexos positivos ou negativos no desenvolvimento das crianças ou dos adolescentes.

O fenômeno conhecido como bullying tem ganhado a cada dia maior relevância na mídia, gerando grande preocupação para pais, professores e sociedade em geral, não podendo ser encarado como um problema apenas da escola, mas de toda a sociedade, notadamente porque o bullying possui características diferentes de outras agressões.

Além do mais, para a materialização dessa agressão, são apresentados quatro elementos: vontade intencionada do autor em ferir a vítima; repetição da agressão; presença de espectadores; e a concordância da vítima com a ofensa.

Para a resolução de conflitos, pode ser utilizada a mediação, levando em consideração as constantes mudanças da sociedade e a necessidade de serem adotadas práticas diferenciadas. Assim, surge a mediação de conflitos, com enfoque sobre a promoção de saúde, educação e segurança, visando à convivência harmônica e ao diálogo como principal ferramenta.

A mediação é utilizada para dirimir conflitos, desde que o terceiro, de modo imparcial e com a devida capacitação, facilite a comunicação entre as partes envolvidas com técnicas de resolução de conflitos baseadas no 
diálogo participativo, efetivo e pacífico, proporcionando solução satisfatória para as partes.

Para construir os argumentos, suas formas de compreensão, o presente estudo parte da inexistência de mecanismos de mediação de conflitos nas escolas de ensino médio e fundamental, visando às práticas de prevenção que podem ser adotadas como ferramenta de enfrentamento contra a violência.

Desse modo, este artigo mostra uma revisão do estado da arte em matéria de mediação de conflitos escolares em casos de bullying, utilizando-se de trabalhos que tratam de problemas similares e/ou correlatos, e cada referência está acompanhada das especificidades do problema abordado, metodologia e limitações. As referências apresentadas pela literatura sobre o tema foram coletadas a partir das bases de dados Medline, SciELO e Lilacs.

\section{MECANISMOS DE PROMOÇÃO EM SAÚDE PÚBLICA EM CASO DE VIOLÊNCIA}

A política de promoção da saúde contribui para a transformação das práticas direcionadas à promoção em saúde púbica em casos de violência. Utiliza-se como base a equidade, a integralidade do cuidado e o respeito à cidadania.

A promoção da saúde oferece condições e instrumentos para ação integrada e interdisciplinar, incluindo diferentes dimensões da experiência humana, social, política, econômica e cultural. Nesse contexto, os saberes e as ações produzidos nos diferentes campos do conhecimento visam promover a saúde, desencadear processos para articular parcerias, atuações intersetoriais e participação popular.

Destacam-se os recursos disponíveis para aplicação em políticas sociais que possuam efetividade diante das necessidades da sociedade, favorecendo a vida sem implicações no desenvolvimento de ações inéditas e redirecionamento no enfoque das políticas públicas.

As estratégias de promoção de saúde e as intervenções intersetoriais contribuem na abordagem de alguns problemas, tais como adoecer 
e ser vítima de violência, resultando em aspectos negativos trazidos por insegurança, medo ou outro tipo de coação que vicia a vontade da pessoa.

Posto isso, a Carta Magna de 1988, em seus artigos 194 e 196, adota como modelo protetivo a Seguridade Social, formalizando aliança entre os poderes públicos e integralizando ações com a sociedade, destinadas a assegurar os direitos relativos à saúde, à previdência e à assistência social. Tais ações potencializam a saúde como direito universal e instituem novo paradigma, como ocorre nos casos de múltipla determinação dos processos de saúde e de doença, inter-relação da política de saúde com as políticas de outras áreas sociais e políticas econômicas (BRASIL, 1988).

\subsection{Conflito}

Entende-se por conflito as opiniões divergentes ou os modos diferenciados de interpretação. O conflito emerge em toda situação social em que as pessoas compartilham espaços, atividades, normas e sistemas de poder. Quando não abordado de forma adequada, desestabiliza a convivência pacífica e gera violência, dificultando o reconhecimento da origem, a natureza do problema (CHRISPINO, 2007).

O aumento progressivo da carga emocional pode desencadear atos de violência, por ela estar intimamente ligada aos modos de reação diante do conflito (LECH, 2008). O conflito, apesar de seus reflexos, não possui apenas aspectos negativos; logo, pode ser algo produtivo e uma oportunidade de crescimento quando as pessoas tomam a consciência da responsabilidade que lhes cabe na origem, no desenvolvimento e na sua resolução (ROCHA; BITTAR; LOPES, 2016).

$\mathrm{Na}$ escola, a convivência de indivíduos diferentes gera conflito, que pode ser construído por meio de duas ideias: uma de violência verbal e física; a outra, de cunho pessoal, com emprego de força excessiva ou moderada. A proliferação do conflito emanado pela violência possui construção respaldada em tais comportamentos no ambiente escolar (ROSA, 2010).

São encontrados nas escolas problemas de diversas espécies; entre eles, o de massificação, resultante da ausência de infraestrutura adequada 
para suportar a quantidade de alunos, tanto em número como em qualidade de ensino (ROCHA; BITTAR; LOPES, 2016).

Assim, a escola é exposta a um contingente de alunos sem o devido suporte para administrar a diversidade e o convívio com as diferenças, resultando em uma relação conturbada e intolerante, de desrespeito ao outro enquanto sujeito de direitos iguais (CHRISPINO, 2007).

\subsection{Violência}

A violência é considerada uma ruptura social pelo uso da força, não possibilita diálogo entre as partes envolvidas e pode ser desencadeada quando o indivíduo impõe força física ou sua influência contra a vítima de forma direta ou indireta (GARBIN; GATTO; GARBIN, 2016).

Dessa forma, atinge milhares de indivíduos em todo o território, tanto em nível nacional como mundial. Conforme constatou o Sistema de Informações sobre Mortalidade, cerca de 59 mil mortes por homicídios foram registradas em 2014 no Brasil, sendo que 11.238 casos envolveram indivíduos entre zero e dezenove anos (BRASIL, 2014).

Consequentemente, a violência pode ocorrer devido a maus-tratos, pais ausentes, irmãos com problemas de comportamento, fácil acesso às armas e às substâncias psicoativas, histórico de comportamentos delituosos, evasão escolar e baixo desempenho acadêmico. Tais circunstâncias fazem com que o indivíduo possa desenvolver comportamentos violentos (SALES, 2016).

No tocante à violência nas escolas, os professores possuem dificuldade de identificá-la, pois entendem que a agressividade é atitude normal na interação entre os alunos. Contudo, quando a agressão ou violência é exteriorizada, sobretudo de forma física, provoca mais espanto e indignação nos sujeitos que presenciam ou vivenciam essa situação (PEDROSA et al., 2016).

A violência contra crianças e adolescentes é tema de relevância social por ser uma realidade vivenciada em lares, nas ruas e nas instituições. A agressividade sofrida ocorre em uma fase que é de extrema relevância para formação psicossocial da pessoa com reflexos na fase adulta (MARQUES, 2014). 
Ao se estar diante de um grupo que apresenta maior vulnerabilidade, cabem, quando necessário, medidas protetivas e socioeducativas, utilizando-se como ferramenta estratégias que envolvam o papel dos adultos na intervenção dos problemas que atingem esses grupos (MARQUES, 2014).

A escola atua como agente de prevenção e proteção, sobretudo quando formalizada a parceria com instituições de ensino superior (IES), de modo a cumprir o seu papel como integrante da rede de proteção e enfrentamento à violência contra crianças e adolescentes.

Em relação à violência escolar no cenário nacional, esse assunto desafia, cada vez mais, professores, pais, gestores e pesquisadores a buscarem soluções efetivas e articuladas com amplos setores da sociedade. A inserção desse fenômeno no escopo dos Direitos Humanos potencializa as respostas sociais a questões derivadas de tais situações (COELHO, 2016).

Diante disso, os métodos de identificação, conscientização e prevenção ao bullying são de responsabilidade das instituições de ensino, para garantir a convivência harmônica e sem violência a fim de estimular o crescimento dos alunos (VENTURA; VICO; VENTURA, 2016).

\subsection{Bullying}

O bullying inclui-se no rol de comportamentos entendidos como agressivos ou violentos. Em geral, o uso do termo no contexto brasileiro alude a comportamentos de intimidação, violência e humilhação, embora o processo não se restrinja somente a essas ações. Em termos conceituais, entende-se que o processo de bullying ocorre na medida em que uma pessoa ou um grupo busca, sistematicamente, excluir, intimidar, molestar ou maltratar outra pessoa ou mesmo um grupo de pessoas, implicando a exclusão social por existir desequilíbrio de poder e a vítima não possuir nenhum recurso de defesa (COELHO, 2016).

Desse modo, "o bullying pode ocorrer tanto de modo direto, através de atos envolvendo agressões físicas e ataques verbais, quanto de modo indireto e relacional, como nas situações de isolamento, chantagem, ameaças, difusão de rumores e fofocas, furtos, entre outros" (COELHO, 2016). 
Em relação à sua ocorrência, o bullying, em termos globais, afeta miIhões de crianças e adolescentes expostos ao fenômeno. No Brasil, os índices de bullying atingem, em parte, alunos matriculados no ensino fundamental, resultando no complexo processo de interações recíprocas entre aspectos individuais e familiares de crianças e de adolescentes.

A Lei n. 13.185, de 2015, conhecida como Lei do bullying, define essa modalidade de violência como física ou psicológica, intencional e repetitiva, sem motivação evidente, praticada por indivíduo ou grupo contra uma ou mais pessoas, objetivando intimidar ou agredir a vítima em uma relação de desequilíbrio de poder entre as partes envolvidas (COELHO, 2016).

O bullying se classifica como: (I) agressão física e material através de socos, tapas, empurrões, chutes, apropriação indevida ou danificação de pertences da vítima; (II) a verbal é desenvolvida com intuito de humilhar a vítima com insultos, ofensas, xingamentos, provocações, ameaças e ridicularização com apelidos perversos; (III) a agressão psicológica tem como elementos perseguir, amedrontar, aterrorizar, intimidar, dominar, manipular, chantagear e infernizar; (IV) a moral consiste em difamar, caluniar, disseminar rumores; ( $V$ ) a sexual tem como objetivo assediar, induzir e/ou abusar; (VI) a virtual tem a finalidade de depreciar, enviar mensagens intrusivas da intimidade, adulterar fotos e dados pessoais que resultem em sofrimento ou com o intuito de criar meios de constrangimento psicológico e social (BRASIL, 2015).

As vítimas de bullying podem desenvolver ansiedade, depressão, solidão, infelicidade e outros problemas relacionados à baixa autoestima, podendo levar também os envolvidos à criminalidade na vida adulta. Desse modo, o bullying é um problema de saúde pública com dimensões cada vez maiores em todos os países (ALVES, 2015).

Por isso, o bullying gera responsabilização pela prática de violência, enseja reparação civil fundamentada no princípio da dignidade da pessoa humana, assegurando a proteção da imagem e honra da criança e do adolescente, conforme estabelece a Constituição Federal. As consequências do bullying podem gerar reparação à vítima, podendo o dano ser patrimonial ou extrapatrimonial, com objetivo de desestimular a prática dessa conduta (SEGUNDO et al., 2015). 
Do mesmo modo, o poder familiar de guarda, de vigilância e de educação dos filhos menores torna os pais como seus responsáveis, devendo reparar quaisquer danos decorrentes de sua conduta (CAMPOS; TORRES; GUIMARÃES, 2004). Por outro lado, os pais, ao deixarem seus filhos na escola, transferem a guarda e a responsabilidade de manutenção da integridade física deles, tornando a escola responsável pelos atos praticados por seus alunos em sua dependência (CHRISPINO; CHRISPINO, 2008).

As escolas estão assumindo um envolvimento crescente na promoção da saúde e na prevenção de doenças; dentre elas, o bullying. O combate a essa violência constitui-se em medida necessária de saúde pública, possibilitando o desenvolvimento de crianças e de adolescentes de forma que estejam habilitados a uma convivência social sadia e segura (ALVES, 2015). Cabe às instituições de ensino adotarem estratégias específicas para conscientização e prevenção ao combate ao bullying (VENTURA; VICO; VENTURA, 2016).

Nesse sentido, a Constituição Federal do Brasil garante a dignidade humana de cada pessoa, relacionada ao devido respeito social, abarcando direitos e deveres fundamentais e assegurando a proteção das pessoas de ameaças desumanas (CHRISPINO; CHRISPINO, 2008).

\subsection{Cyberbulling}

Com o crescimento acelerado da tecnologia, manifestou-se uma nova figura de intimidação, a qual ultrapassa o aspecto físico e presencial, chamada de cyberbullying, uma modalidade de bullying em que as agressões são virtuais, praticadas por meios tecnológicos (JAHNKE; GAGLIETTI, 2012).

O cyberbullying pode ser compreendido como uma modalidade específica de bullying, que se configura por instrumentos tecnológicos, tais como telefones celulares e internet, impactando comportamentos praticados entre pares no ambiente virtual.

Desse modo, o cyberbullying ocorre quando alguém executa, proativa e repetidamente, atitudes sobre determinada pessoa em contextos virtuais, assediando por e-mails ou mensagens com temas não apreciados pela vítima. A intencionalidade é levada em consideração, pois determina 
o comportamento não apenas como uma brincadeira aleatória, mas em ato que resulta em danos.

Entretanto, quando um adolescente exerce tanto um papel de agressor como de vítima, pode ser delineado um perfil que o caracteriza como vítima-agressor. Do mesmo modo como ocorre nas situações de bullying, os indivíduos que acompanham - ou assistem - aos episódios de agressão podem ser caracterizados como espectadores e, além disso, aqueles que por ventura se divertem ou mesmo compartilham os episódios podem ser compreendidos como apoiadores ou incentivadores do processo. (WENDT; LISBOA, 2014).

Vale ressaltar que o cyberbullying não é uma experiência face a face, mas que ocorre sempre por meio de recurso tecnológico. Assim, possibilita ao agressor ficar anônimo, diferentemente da maior parte dos casos típicos de bullying (agressões físicas, insultos verbais, chantagem).

Isto é percebido em casos de bullying em que os agressores também podem ficar anônimos, utilizando, principalmente, formas indiretas de agressividade, como fofocas, propagação de rumores, difamação da imagem de pessoas, entre outras. Entretanto percebe-se que, na maioria das vezes, os agressores são identificados e têm seus comportamentos reforçados pelos pares. A opção pelo anonimato, nos casos de cyberbullying, pode ser compreendida a partir do chamado efeito da desinibição, ou seja, as pessoas podem sentir confiança e coragem "diante da possibilidade de serem anônimas" (WENDT; LISBOA, 2014).

Nesse contexto, o agressor utiliza-se de suas habilidades tecnológicas para intimidar as vítimas, tendo em vista que cada vez mais crianças e adolescentes usam a internet e o celular. Consequentemente, aumenta-se a vulnerabilidade dessa modalidade de violência, que pode gerar depressão, isolamento, baixa autoestima e outros, fazendo com que o sofrimento da vítima se estenda para além da escola, com impacto no rendimento escolar e na vida adulta (SANTOS; COSTA-FILHO, 2014).

Todavia, destaca-se que o aparecimento do cyberbullying deve-se, sobretudo, a alguns fatores, tais como ampliação das redes sociais e surgimento de novos sites de relacionamento, blogs e fotoblogs populares entre adolescentes. Ainda falta orientação a esses adolescentes a respeito da responsabilidade de quem pratica cyberbullying (JAHNKE; GAGLIETTI, 2012). 
O cyberbullying apresenta como particularidade de assédio a velocidade de propagação das informações nos meios virtuais, invadindo os ambientes de privacidade e segurança, configurando-se como uma extensão além do pátio da escola (JAHNKE; GAGLIETTI, 2012).

\section{DIREITOS DA PERSONALIDADE}

Os direitos da personalidade possuem características especiais e são destinados à proteção da pessoa, de modo a assegurar sua dignidade como valor fundamental. Esses direitos são inatos, já nascem com a pessoa, "absolutos, extrapatrimoniais, intransmissíveis, imprescritíveis, impenhoráveis, vitalícios, necessários e oponíveis erga omnes" (BITTAR, 2006, p. 11).

Nesse contexto, o respeito à dignidade humana encontra-se entre os fundamentos constitucionais pelos quais se orienta o ordenamento jurídico brasileiro na defesa dos direitos da personalidade na Constituição Federal de 1988, artigo 1으, inciso III.

Assim, a dignidade humana não deve ser valorizada e nem substituída por ser um atributo natural. Ela possui valor intrínseco e absoluto, abrange direitos como a vida, a liberdade, a igualdade, o respeito e a consideração, o trabalho, a assistência social, ou seja, tudo aquilo que constitui vida digna para o desenvolvimento e a convivência na sociedade.

A prática de bullying viola o direito à intimidade, que, por ser inviolável, inalienável, imprescritivel e irrenunciável, deve ser respeitado, pois a dignidade humana depende de sua observância, visando proteger a vida privada e resguardar os direitos, a privacidade do indivíduo.

A proteção dos direitos da personalidade pode ser feita em diversas áreas do ordenamento jurídico. Assim, há vários estatutos disciplinadores que dão enfoque a esse assunto. A proteção dos direitos da personalidade é, basicamente, o dever de reparar os danos causados, além do direito de fazer cessar a lesão.

Desse modo, o art. 5o do Estatuto da Criança e do Adolescente (ECA) estabelece que "nenhuma criança ou adolescente será objeto de qualquer forma de negligência, discriminação, exploração, violência, crueldade e opressão, punido na forma da lei qualquer atentado, por ação ou omissão, 
aos seus direitos fundamentais"; e o art. 17 do ECA assegura que "o direito ao respeito consiste na inviolabilidade da integridade física, psíquica e moral da criança e do adolescente, abrangendo a preservação da imagem, da identidade, da autonomia, dos valores, ideias e crenças, dos espaços e objetos pessoais" (BRASIL, 1990).

A criança e o adolescente têm direito ao respeito à sua dignidade e à inviolabilidade de sua integridade física e mental. Quaisquer violações dos direitos das crianças e dos adolescentes desrespeitam as prerrogativas dos direitos fundamentais assegurados pela Declaração de Genebra de 1924 (art. 1ㅇ); Declaração Universal dos Direitos do Homem de 1948 (art. 25, II); Declaração dos Direitos da Criança da ONU de 1959 (princípios I, II, VII e VIII); Pacto Internacional sobre Direitos Civis e Políticos de 1966 (art. 24, 1); Convenção sobre os Direitos da Criança de 1989 (art. 3이 I); Constituição Federal de 1988 (arts. 5ํ, II, III, X, XV, XX, XLI; XLII, 53, 205, 227) e Estatuto da Criança e do Adolescente (DINIZ, 2017).

Na defesa de qualquer direito da personalidade violado ter-se-á como paradigma o respeito à dignidade da pessoa humana, que é o fundamento do Estado Democrático do Direito (CF, art. 1ํ, III) e o cerne de todo o ordenamento jurídico. Deveras, a pessoa humana e sua dignidade constituem fundamento e fim da sociedade e do Estado, sendo o valor que prevalecerá sobre qualquer ato de violência. Consequentemente, não se poderá, como no caso de bullying ou cyberbullying, admitir conduta que venha a reduzir a pessoa humana à condição de coisa, retirando dela sua dignidade e o direito a uma vida digna. (DINIZ, 2017, p. 636).

Ressalta-se que o princípio da dignidade humana na sociedade fundamenta-se na liberdade, igualdade, fraternidade e solidariedade entre as pessoas e, nesse sentido, o art. 1ㅇ da Declaração Universal dos Direitos Humanos determina que "todos os seres humanos nascem livres e iguais em dignidade e em direitos. Dotados de razão e consciência, devem agir uns para com os outros com espírito de fraternidade" (Declaração Universal dos Direitos Humanos - ONU, 1948, p. 4).

Assim, se houver bullying ou cyberbullying, por ser ato atentatório à dignidade humana e aos direitos da personalidade, ele deverá ser repudiado por contrariar as exigências ético-jurídicas dos direitos 
humanos, para que haja efetividade dos direitos da personalidade de todos os integrantes da comunidade educacional (DINIZ, 2017, p. 637).

Nessa perspectiva, considerar a dignidade humana como valor supremo e fundamento primário do ordenamento jurídico brasileiro, como princípio-base em toda relação humana, implica o dever, o respeito e a consideração com o outro.

Nesse sentido, o bullying constitui-se em flagrante atentado à dignidade humana e aos direitos da personalidade, que estão intimamente relacionados, gerando "responsabilidade civil por dano moral. Isto é assim, porque, como ensina Sérgio Cavalieri Filho, a dignidade humana é a base de todos os valores morais e a essência dos direitos personalíssimos" (DINIZ, 2017, p. 637).

A proteção da dignidade e da personalidade de todos os indivíduos está resguardada pelo sistema legal, impondo o dever de não lesar por ato concreto ou simples ameaça à personalidade e à dignidade de outrem, sob pena de reparar o dano moral e material que a ofensa à personalidade de outrem gerar.

A integridade psíquica pode ser agredida, do mesmo modo e de forma predominante, a estrutura psíquica, causando-lhe uma lesão que repercute na saúde do sujeito; estas lesões podem ser consequências de uma prévia agressão físico-corpórea ou podem também apresentar-se desvinculadas da mesma; esse dano à pessoa, por sua vez, podem ter consequências patrimoniais e/ou extrapatrimoniais: o agravo à esfera psíquica do sujeito, que integra com o corpo (soma) uma unidade, pode incidir, em particular, sobre algum dos três aspectos em que, teoricamente, se apresenta a estrutura psíquica do ser humano; pode ocasionar um dano psíquico ao atuar, primariamente e segundo circunstâncias, sobre os sentimentos, a vontade ou o intelecto, ou sobre os três, em conjunto. Pode, assim, provocar uma lesão psíquica em função dos sentimentos do sujeito; sentimentos, sensibilidade que, como sabido, variam de pessoa a pessoa; a pena, o sofrimento, a dor de afeição, produto do dano, terá provavelmente maior intensidade e duração em pessoas extremamente sensíveis; esse específico dano, causado à esfera sentimental do sujeito, é conhecido, tradicionalmente, pela expressão dano moral; este dano, por outro lado, era o único dano à pessoa juridicamente reconhecido e digno de reparação até faz pouco tempo; É possível, ainda assim, causar outra variante de dano 
a integridade psíquica da pessoa, relacionado primariamente com a vontade e o intelecto; pode atuar para anular ou limitar a vontade de uma pessoa ou para diminuir a sua capacidade intelectual. (CAHALI, 1989, p. 188-9).

Ainda, na relação aluno e professor, em que o mestre assume o papel de condutor e mediador do processo ensino-aprendizado e detém o poder e a autoridade em relação ao aluno, essa relação implica respeito, consideração e dever de obediência. Quando essa relação se torna inexistente, o aluno, pela prática do bullying, busca atingir a pessoa do professor e depreciá-lo publicamente. Ocorrem os danos à integridade e "o direito à integridade psíquica opõe-se a qualquer meio externo, humano ou técnico, tendente a alterar a mente de outrem ou a inibir sua vontade, sancionando-se ao atentado em nível penal e civil" (BITTAR, p. 120, 2006).

$\mathrm{E}$, nesse contexto, o bullying pode ser praticado de forma insidiosa ou declarada e atinge o direito à personalidade do professor, utilizando-se de agressão e comentários pejorativos e injuriosos, que podem causar consequências danosas na esfera pessoal e profissional.

Nesse paradigma, o ordenamento jurídico busca resguardar direitos inerentes à pessoa humana, a fim de que as transformações da vida no cenário social e político exijam respostas, formas de pensar e sentir, formando modelos de comportamento.

\section{O BULLYING E O ESTATUTO DA CRIANÇA E DO ADOLESCENTE}

A criança e o adolescente recebem proteção integral e atenção prioritária da família, da sociedade e do Estado, objetivando que se desenvolvam adequadamente, livres de qualquer tipo de agressão (art. 227 da CF, art. $3 \circ$ e 4 ㅇ do ECA).

O bullying viola diversos direitos fundamentais positivados no artigo 5 o da Constituição Federal, que determina a igualdade de todos perante a lei, sem distinção de qualquer natureza. Ainda, é garantida a inviolabilidade do direito à vida, à liberdade, à igualdade, à segurança e à propriedade.

Ao considerar os sérios reflexos na vida adulta do indivíduo, é fundamental que crianças e adolescentes sejam protegidos integralmente de fatores que causam danos ao seu desenvolvimento. 
O bullying praticado por criança e adolescente pode consubstanciar um ato infracional, nos termos do art. 103 do ECA, como em casos de agressões verbais que podem culminar em atos infracionais análogos aos crimes de injúria ou injúria racial. Quando há ameaças, pode configurar o ato infracional análogo ao crime de ameaça. Por fim, caso haja violência física, poderá incidir em lesão corporal etc.

Desse modo, há de se considerar que a maior consequência da prática do bullying está na formação da criança e do adolescente, visto que a escola é um ambiente que influencia no desenvolvimento integral do indivíduo, e a violência, sem o devido acolhimento, poderá causar uma marca traumática durante o desenvolvimento desses indivíduos, com sérias repercussões na fase adulta.

\section{MEDIAÇÃO DE CONFLITOS}

No Brasil, a Lei n. 13.140/2015 considera a mediação de conflitos atividade técnica exercida por terceiro imparcial, sem poder decisório, que, escolhido ou aceito pelas partes, auxilia-as a identificar ou a desenvolver soluções consensuais para a controvérsia (BRASIL, 2015). A mediação é uma prática que busca solucionar um conflito de forma pacífica por meio de um terceiro imparcial de modo a facilitar o diálogo (SILVA et al., 2016).

Para realizar a mediação de conflitos, devem ser respeitados determinados princípios, como a imparcialidade, a isonomia entre as partes, a oralidade, a informalidade, a autonomia de vontade das partes, a confidencialidade e a boa-fé na condução adequada do trâmite de mediação de conflitos (SALES, 2015).

A mediação tem como objetivo principal solucionar, manter, reestabelecer vínculos e pacificar as relações individuais e coletivas. Para facilitar tal pacificação, o mediador deve transmitir e buscar a cooperação entre os envolvidos, transmitindo segurança e tranquilidade aos mediados (FEIJÓ et al., 2011).

O mediador precisa manter a atenção no decorrer da resolução, conforme a complexidade dos conflitos, pois existem conflitos que não refletem a verdadeira causa de angústia, insatisfação, intranquilidade ou outro 
sentimento que provoque o mal-estar. Por isso, é necessária a utilização de diálogo participativo e verdadeiro para alcançar a origem do conflito (SALES; CHAVES, 2014).

Para resolver problemas não relacionados à justiça, o indivíduo pode recorrer ao mediador extrajudicial para resolução de conflitos do dia a dia (CAMPOS; TORRES; GUIMARÃES 2004). Poderá exercer a função de mediador extrajudicial qualquer pessoa capaz que tenha a confiança das partes e seja capacitada para fazer mediação, independentemente de integrar qualquer tipo de conselho, entidade de classe ou associação (BRASIL, 2015).

\subsection{Mediação de conflitos em ambiente escolar}

O papel da escola no auxílio da mediação de conflitos possui grande importância, tendo em vista que é palco de conhecimento, por isso os dados sobre a divulgação dos direitos humanos requerem que o educador transmita conhecimentos sobre esses direitos, utilizando-se de experiências que possam contribuir para a instituição da paz entre alunos, agregando pessoas, produzindo atividades, formando ou se associando a redes de promoção de Direitos Humanos (COELHO, 2016).

Desse modo, as experiências pessoais e a forma como a mídia ou a literatura abordam o problema influenciam os modos de perceber e definir a violência. Portanto é possível estabelecer parâmetros da relação professor e aluno, que pode ser utilizada como guia na prevenção de comportamentos violentos na escola, ao redor dela, ou em outros espaços, por meio da intervenção (COELHO, 2016).

A mediação de conflitos escolar é uma ferramenta utilizada em negociações que visa à solução de conflitos entre as partes envolvidas, funciona como instrumento de pacificação, auxilia na educação e produz mudanças positivas (VENTURA; VICO; VENTURA, 2016). Logo, não deve ser desenvolvida apenas quando já existe um problema, mas, sim, como meio eficaz na prevenção de práticas que podem desestabilizar o ambiente (FEIJÓ et al., 2011).

O reconhecimento de comportamento negativo e as agressões entre alunos interferem diretamente na administração escolar. A sobrecarga dos 
profissionais de ensino gera distanciamento dos alunos. Outro fator negativo é a ausência dos pais em suas atribuições básicas na educação e no acompanhamento de seus filhos, transferindo tais responsabilidades para a equipe escolar (VENTURA; VICO; VENTURA, 2016).

A incidência de violência escolar é tema de grande relevância na vida em comunidade, que deve ser erradicada com a finalidade de evitar maiores prejuízos. Nesse contexto, surge o mediador de conflitos, sendo o sujeito que favorece a interpretação do problema e atribui significado à informação recebida, visando estimular o equilíbrio no ambiente escolar (ROCHA; BITTAR; LOPES, 2016).

Para a execução da mediação, o local deve preservar a intimidade, com condições que não provoquem desordens e incômodos no ambiente que foi selecionado para mediar conflitos, pois a mobilidade facilita o contato visual direto entre as partes (VENTURA; VICO; VENTURA, 2016).

A mediação contribui para a solidificação da autoestima, por intermédio de técnicas aplicadas por pessoas legitimadas, que levam em consideração as características de cada sujeito mediado. No decorrer desse processo, os indivíduos aprendem que devem ser protagonistas nas soluções de seus problemas. A mediação pode também contribuir para que a criança tome mais iniciativa mediante diferentes contextos, sem deixar que esse processo siga automaticamente, e para encorajar a criança a ser menos passiva no ambiente.

Nesse sentido, tal técnica possibilita a reação positiva diante dos problemas originários, pois, em muitos casos, uma delinquência ou conflito social iniciam-se na escola. A conciliação escolar objetiva um acordo mútuo e aceitável, o qual contribui para novas formas de cooperação nas escolas, exercendo a solidariedade e a reorientação das relações pessoais (ROCHA; BITTAR; LOPES, 2016).

Em síntese, a mediação pode ser aplicada em todos os setores da escola, a fim de intervir em sua organização e objetivar uma convivência harmônica entre todos os integrantes, de forma que identifique e mostre a capacidade de cada indivíduo em resolver seus problemas por meio do diálogo, para reduzir possíveis níveis de tensão (MORGADO; OLIVEIRA, 2009). 


\section{RESPONSABILIDADE CIVIL}

Responsabilidade é um termo que remete a todos os âmbitos da vida social; no plano jurídico, é utilizado normalmente por quem responde ou se responsabiliza por certa atividade e pelos danos dela decorrentes. Assim, o indivíduo será responsabilizado civilmente quando houver dano a outrem, contrariando norma legal.

Nesse contexto, a responsabilidade civil possui como fundamento o princípio romano neminem laedere, o dever de conduta atribuído a cada indivíduo de viver honestamente e não causar prejuízos a outrem (REIS, 2000). Não há como viver em sociedade sem exigir o mínimo de comportamento de cada ser humano.

[...] a responsabilização é meio e modo de exteriorização da própria justiça, e a responsabilidade é a tradução para o sistema jurídico do dever moral de não prejudicar outra pessoa, ou seja, o neminem laedere. A ninguém é permitido lesar o seu semelhante. O sistema de Direito positivo estabelecido repugna tanto a ofensa ou a agressão física como moral, seja impondo sanção de natureza penal, ou de natureza civil, também sancionatória, mas de caráter pecuniário, ainda que se cuide de ofensa moral. A primeira visa à pacificação social e à defesa da sociedade; a segunda tem caráter individual ou unitário e tem por escopo a proteção da pessoa. (STOCO, 2007, p. 115).

O dever de reparar, indenizar, será correspondente à ofensa de atributos como a honra, a imagem, o bom nome, a intimidade, a privacidade, enfim, todos os atributos da personalidade (STOCO, 2007). Nos termos do Código Civil, a responsabilidade civil deve ser imputada quando:

Art. 949. No caso de lesão ou outra ofensa à saúde, o ofensor indenizará o ofendido das despesas do tratamento e dos lucros cessantes até ao fim da convalescença, além de algum outro prejuízo que o ofendido prove haver sofrido.

Art. 950. Se da ofensa resultar defeito pelo qual o ofendido não possa exercer o seu ofício ou profissão, ou se lhe diminua a capacidade de trabalho, a indenização, além das despesas do tratamento e lucros cessantes até ao fim da convalescença, incluirá pensão correspondente à importância do trabalho para que se inabilitou, ou da depreciação que ele sofreu. (BRASIL, 2002, p. 1). 
As consequências jurídicas do bullying na esfera civil são decorrentes da não observância das normas de condutas, o que causa o dever de indenizar, tendo em vista que o bullying é um comportamento ilícito e antijurídico que gera dano, lesa, causa prejuízos às vítimas dessa agressão.

O prejuízo ou dano é moral ou extrapatrimonial, já que fere a dignidade e a personalidade da vítima. Qualquer que seja a natureza do dano (extrapatrimonial ou patrimonial) traz a correlata obrigação de reparar o mal causado (NASCIMENTO; ALKIMIN, 2010).

Dessa forma, a consequência imediata do bullying é o dano moral, que se traduz em lesão a direito da personalidade e não possui ligação com perda de patrimônio ou perda pecuniária, mas, sim, com a reputação da vítima; logo, incorre na obrigação de indenizar, consequência jurídica do ato ilícito, ficando os bens do agressor sujeito à reparação do dano causado.

Dano moral é o prejuízo que afeta o ânimo psíquico, moral e intelectual da vítima. Sua atuação é dentro dos direitos de personalidade. Nesse campo, o prejuízo transita pelo imponderável, daí por que aumentam as dificuldades de se estabelecer a justa recompensa pelo dano. Não é também qualquer dissabor comezinho da vida que pode acarretar a indenização [...]. (VENOSA, 2006, p. 35).

A indenização por danos morais tem por finalidade minorar o sofrimento do ofendido e punir o ofensor para que não haja reincidência da prática de tal conduta ilícita e antijurídica. Essa punição não deve gerar o enriquecimento sem causa da vítima. É crível que a indenização não visa ressarcir os prejuízos morais e psíquicos, mas tem por finalidade compensar a dor, o sofrimento íntimo e a angústia que atingem a vítima da violência.

As escolas públicas são consideradas pessoas jurídicas de direito público e têm responsabilidade jurídica como instituições de ensino, cuja atividade corresponde à prestação de serviços públicos sob controle estatal e visa satisfazer as necessidades essenciais da coletividade, enquanto as escolas particulares são consideradas pessoas jurídicas de direito privado, prestadoras de serviços públicos por delegação do Estado.

Assim, as instituições de ensino devem zelar pela integridade física e psíquica de seus alunos e professores, possuem o dever de vigiar, fiscalizar 
e empreender medidas que visem prevenir e evitar que a escola seja um cenário para a prática do bullying.

\subsection{Responsabilidade civil dos pais}

Em casos de bullying no âmbito escolar, realizados por crianças e adolescentes, a regra está estabelecida pelo art. 932, inciso I e II do Código Civil: "São também responsáveis pela reparação civil: I- os pais, pelos filhos menores que estiverem sob sua autoridade e em sua companhia; Il- o tutor e o curador, pelos pupilos e curatelados, que se acharem nas mesmas condições".

A responsabilidade jurídica dos pais nasce com o dever de indenizar, sendo facultado à vítima do bullying exigir esse dever de reparação dos prejuízos experimentados por meio da ação de indenização.

Aos pais, detentores do poder familiar e do exercício do direito de guarda e de proteção em relação à pessoa dos filhos menores, incumbe o dever de incutir princípios morais na formação de seus filhos, sob pena de responder pelo pagamento da indenização causada por bullying praticado na escola.

É importante ponderar que, no caso de incapacidade, tanto absoluta como relativa, nos termos do art. 928 do Código Civil, "o incapaz responde pelos prejuízos que causar, se as pessoas por ele responsáveis não tiverem obrigação de fazê-lo ou não dispuserem de meios suficientes", uma vez que a indenização prevista nesse artigo deverá ser equitativa, não terá lugar se privar do necessário o incapaz ou as pessoas que dele dependem. Nesse contexto, a conscientização dos responsáveis pela criança ou pelo adolescente sobre a prática de bullying existente é o primeiro meio de solucionar o problema.

\subsection{Responsabilidade civil da escola}

A escola, ao receber o estudante menor de idade, confiado ao estabelecimento de ensino, está investida no dever de guarda e de preservação da integridade física do aluno, obrigando-se a empregar vigilância para prevenir e evitar qualquer ofensa ou dano aos seus alunos, que possam prejudicar o convívio escolar. 
A ideia de vigilância é mais ampla do que a de educação, devendo entender-se que estas pessoas respondem pelos atos dos alunos e aprendizes, durante o tempo em que eles exercem vigilância e autoridade. Os danos por que respondem são, ordinariamente, os sofridos por terceiros, o que não quer dizer que os danos sofridos pelo próprio aluno ou aprendiz não possam acarretar a responsabilidade do mestre ou diretor do estabelecimento. (GONÇALVES, 2012 p. 158).

No caso de bullying ou violência, a escola é responsável, uma vez que seu papel é proteger e desenvolver medidas e ações que preservem a integridade física e psicológica de seus alunos, para integrar seus alunos ao meio social.

Desse modo, observa-se que a responsabilidade civil dos estabelecimentos de ensino impõe um dever de cuidado a essas instituições. A responsabilização, obviamente, dependerá de cada caso, das circunstâncias e do modo como foi ou não exercido o cuidado necessário na preservação de um relacionamento escolar apto a evitar os danos de uma ação violenta.

\section{CONSIDERAÇÕES FINAIS}

Considerar a dignidade humana como valor supremo e fundamento primário do ordenamento jurídico brasileiro, norte de todas as relações humanas, implica o dever de respeito e de consideração à pessoa do outro. Não se admite em uma sociedade compromissada com a efetiva tutela da pessoa humana qualquer forma de violência, sobretudo quando praticada contra os mais vulneráveis: crianças e adolescentes cuja personalidade está em constante formação.

O bullying é uma forma de violência que tem ocupado o centro da atenção de professores, pais e alunos, já que parte de pequenas investidas contra os direitos da personalidade de outrem, podendo atingir casos mais graves, que levam às agressões físicas e à própria morte. Essa prática tem ganhado maior sofisticação à medida que se amplia o acesso às tecnologias, sendo utilizados celulares, blogs e outros meios digitais na Internet. Trata-se de uma forma mais sofisticada de bullying, o chamado cyberbullying.

Envolver todos os atores sociais na busca de soluções é uma das principais estratégias no seu enfrentamento, sendo a prática da mediação uma 
eficiente alternativa. Por meio dela, as próprias partes envolvidas no litígio conversam, refletem sobre a conduta e constroem um compromisso de boa convivência, mediante o auxílio de um terceiro imparcial e comprometido com a pacificação social.

Caso o conflito não possa ser resolvido no âmbito extrajudicial, por meio da mediação, ainda resta uma medida mais drástica: a tutela jurisdicional por meio da responsabilidade civil. Assim, os pais serão responsabilizados pelos danos morais e patrimoniais praticados por seus filhos menores de idade, à luz do que dispõe o Código Civil brasileiro. As escolas também serão responsabilizadas caso se mantenham inertes diante de um caso de bullying praticado nas suas dependências.

\section{REFERÊNCIAS}

ALVES, C. F. Bullying: gestão escolar e a saúde pública, uma revisão da literatura. Revista Eletrônica Gestão \& Saúde, Brasília, v. 6, n. 3, p. 2919-33, 2015.

BITTAR, Carlos Alberto. Os direitos da personalidade. 7. ed. Rio de Janeiro: Forense Universitária, 2006.

BRASIL. Constituição da República Federativa do Brasil de 1988. Brasília, DF, 1988.

BRASIL. Lei n. 10.406, de 2002. Dispõe sobre o Código Civil Nacional. Brasília-DF, 2002. Disponível em: http://www.planalto.gov.br/ccivil_03/leis/2002/l10406.htm. Acesso em: 12 abr. 2020.

BRASIL. Lei n. 13.140, de 26 de junho de 2015. Dispõe sobre a mediação entre particulares como meio de solução de controvérsias e sobre a autocomposição de conflitos no âmbito da administração pública; altera a Lei n. 9.469, de 10 de julho de 1997, e o Decreto n. 70.235, de 6 de março de 1972; e revoga o $\S 2^{\circ}$ do art. $6^{\circ}$ da Lei n. 9.469, de 10 de julho de 1997. Brasília, DF, 2015. Disponível em: http://www.planalto.gov.br/ccivil_03/_ato2015-2018/2015/Lei/L13140.htm. Acesso em: 10 abr. 2020.

BRASIL. Lei n. 8.069, de 13 de julho de 1990. Dispõe sobre o Estatuto da Criança e do Adolescente e dá outras providências. Brasília, DF, 1990. Disponível em: http:// www.planalto.gov.br/Ccivil_03/leis/L8069.htm. Acesso em: 10 abr. 2020. 
BRASIL. Ministério da Saúde. Importância dos sistemas de informações sobre mortalidade e nascidos vivos para os profissionais do Programa Saúde da Família. Brasília, DF: Fundação Nacional de Saúde, 2014.

CAHALI, Y. S. Dano Moral. São Paulo: Revista dos Tribunais, 1998.

CAMPOS, P. H. C.; TORRES, A. R. R.; GUIMARÃES, S. P. Sistemas de representação e mediação simbólica da violência na escola. Revista Educação e Cultura Contemporânea, São Paulo, v. 1, n. 2, p. 109-32, 2004.

CHRISPINO, A. Gestão do conflito escolar: da classificação dos conflitos aos modelos de mediação. Revista Ensaio: Avaliação e Políticas Públicas em Educação, Rio de Janeiro, v. 15, n. 54, p. 11-28, jan./mar. 2007.

CHRISPINO, A.; CHRISPINO, R. S. P. A judicialização das relações escolares e a responsabilidade civil dos educadores. Revista Ensaio: Avaliação e Políticas Públicas em Educação, Rio de Janeiro, v. 16, n. 58, p. 9-30, jan./mar. 2008.

COELHO, M. T. B. F. School bullying: a systematic review of the literature from 2009 to 2014. Revista Psicopedagogia, São Paulo, v. 33, n. 102, p. 319-30, 2016.

DINIZ, M. H. Bullying e suas consequências jurídicas. Revista Jurídica Luso-Brasileira, Lisboa, v. 3, n. 2, p. 625-61, 2017. Disponível em: http://www.planalto.gov.br/ ccivil_03/Constituicao/Constituicao.htm. Acesso em: 15 abr. 2020.

FEIJÓ, M. R.; STELATA, P. L.; TOLEDO, M.; BONDUKI, L.; CHIARETO, A.; CIASCA, D.; LEMBO, O.; LIMA, R. M.; HELENA, I.; CALANO, M.; SILVA, J.; CECCI, C. A construção de um projeto de mediação de conflitos e cultura e paz: etapas e desafios. Revista Nova Perspectiva Sistêmica, Rio de Janeiro, n. 40, p. 83-98, ago. 2011.

GARBIN, C. A. S.; GATTO, R. C. J.; GARBIN, A. J. I. Prevalência de bullying em uma amostra representativa de adolescentes brasileiros. Archives of Health Investigation, Araçatuba, v. 5, n. 5, p. 256-61, 2016.

GONÇALVES, C. R. Responsabilidade civil. 14. ed. São Paulo: Saraiva, 2012.

JAHNKE, L. T.; GAGLIETT, M. O avanço tecnológico e os conflitos comportamentais nas redes sociais - o cyberbullying. In: CONGRESSO INTERNACIONAL DE DIREITO E CONTEMPORANEIDADE, 1., 30-31 maio e 1o jun. 2012, Santa Maria, RS. Anais [...]. Santa Maria, 2012. 
LECH, M. B. Como lidar com os conflitos na escola. Revista Direcional Educador, São Paulo, v. 3, n. 36, p. 7, jan. 2008.

MARQUES, J. A. M. Violência e vitimização na infância e adolescência - a inclusão da escola no reconhecimento e prevenção. Ciência \& Saúde Coletiva, Feira de Santana, v. 19, n. 3, p. 985-93, 2014.

MORGADO, C.; OLIVEIRA, I. Mediação em contexto escolar: transformar o conflito em oportunidade. Exedra: Revista Científica, Coimbra, n. 1, p. 43-56, jun. 2009.

NASCIMENTO, G. A. F.; ALKIMIN, M. A. Violência na escola: o bullying na relação aluno-professor e a responsabilidade jurídica. In: ENCONTRO NACIONAL DO CONPEDI, 19., 9-12 jun. 2010, Fortaleza. Anais [...]. Fortaleza, 2010.

ORGANIZAÇÃO DAS NAÇÕES UNIDAS. Declaração Universal dos Direitos Humanos de 1948. ONU, 2009. Disponível em: https://nacoesunidas.org/wp-content/ uploads/2018/10/DUDH.pdf. Acesso em: 10 abr. 2020.

PEDROSA, S. M.; GONTIJO, D. T.; SOUZA, M. M.; SILVA, M. A. I.; MEDEIROS, M. Violência no contexto escolar: significados para professores do ensino público. Revista Ciência, Cuidado e Saúde, Maringá, v. 15, n. 3, p. 397-404, jul./set. 2016.

REIS, C. Responsabilidade Civil do Médico. Revista de Direito Privado e Processual, Maringá, v. 1, n. 1, jun. 2000.

ROCHA, M. F. R.; BITTAR, J.; LOPES, R. E. O professor mediador escolar e comunitário: uma prática em construção. Revista Eletrônica de Educação, v. 10, n. 3, p. 341-53, 2016.

ROSA, M. J. A. violência no ambiente escolar: refletindo sobre as consequências para o processo ensino aprendizagem. Revista Fórum Identidades, v. 8, n. 8, p. 144-58, jul./dez. 2010.

SALES, L. M. M.; CHAVES, E. C. C. Mediação e conciliação judicial - a importância da capacitação e de seus desafios. Revista Sequência, Santa Catarina, n. 69, p. 255-80, dez. 2014.

SALES, L. M. Sistema de justiça, mediação de conflitos e o aprimoramento de suas técnicas. Revista Prima Facie, João Pessoa, v. 14, n. 27, p. 1-2, 2015.

SALES, S. S. Elaboração do protocolo para avaliação forense de adolescentes em acolhimento institucional. 2016. Dissertação (Mestrado em Psicologia) Universidade Tuiuti do Paraná, Curitiba, PR, 2016. 
SANTOS, N. C. N.; COSTA-FILHO, P. M. Vivendo esse mundo digital: impactos na saúde, na educação e nos comportamentos sociais. Ciência \& Saúde Coletiva, v. 19, n. 3, p. 985-93, 2014.

SEGUNDO, P. R. R. E.; SOUZA, A. F. G.; SOUZA, D. K.; OLIVEIRA, H. G.; BUENO, F. F.; PRANDIN, L. R. BULLYING ESCOLAR: Os danos sociais e os aspectos jurídicos do fenômeno. Educere - Revista da Educação, Paraná, v. 15, n. 2, p. 219-37, jul./dez. 2015.

SILVA, A. O.; ARAÚJO, C. R. F., SANTOS, M. A. C.; PITTMAN, M. C. B. T. Mediação como instrumento para justiça da paz. Revista do Curso de Direito da FSG, Caxias do Sul, v. 10, n. 19, p. 36-55, 2016.

STOCO, R. Tratado de responsabilidade civil: doutrina e jurisprudência. 7. ed. rev., atual. e ampl. São Paulo: Revista dos Tribunais, 2007.

VENOSA, S. S. Direito Civil, Editora Atlas: São Paulo, 6. ed. 2006.

VENTURA, A. V.; VICO, B. P.; VENTURA, R. Bullying e formação de professores: contributos para um diagnóstico. Revista Ensaio: avaliação políticas públicas em Educação, Rio de Janeiro, v. 24, n. 93, p. 990-1012, out./dez. 2016.

WENDT, G. W.; LISBOA, C. S. M. Compreendendo o fenômeno do cyberbullying. Revista Temas em Psicologia, São Paulo, v. 22, n. 1, p. 39-54, 2014. 
